\title{
INFLUÊNCIA DE BACILLUS SUBTILIS NA ECLOSÃO, ORIENTAÇÃO E INFECÇÃO DE HETERODERA GLYCINES EM SOJA
}

\author{
INFLUENCE OF BACILLUS SUBTILIS ON THE HETERODERA GLYCINES \\ ECLOSION, ORIENTATION AND INFECTION IN SOYBEAN
}

\author{
Fábio Fernando de Araújo ${ }^{1}$ João Flávio Veloso Silva ${ }^{2}$ \\ Ademir Sérgio Ferreira de Araújo ${ }^{3}$
}

RESUMO

A utilização de microrganismos para fins de controle biológico de doenças em plantas tem sido muito estudada no mundo. No caso do nematóide de cisto da soja (Heterodera glycines), uma das principais doenças da soja, o controle biológico é de grande importância devido à ausência de controle químico eficiente. Para se estudar o efeito de Bacillus subtilis sobre $\boldsymbol{H}$. glycines, foram conduzidos alguns experimentos de casa de vegetação e laboratório. Nos trabalhos de laboratório, verificou-se, em câmara de eclosão, que a presença de $\boldsymbol{B}$. subtilis reduz a eclosão de ovos de $\boldsymbol{H}$. glycines estimulados com exsudatos de sementes de soja. Foi observado também que o tratamento de raiz de soja com a bactéria inibiu a migração de larvas juvenis de $\boldsymbol{H}$. glycines para a planta em comparação à raiz não tratada com a bactéria. Nos ensaios de casa de vegetação, utilizando-se vasos com solo infestados com ovos de $\boldsymbol{H}$. glycines, observou-se uma redução de fêmeas na raiz de soja quando o solo ou sementes foram tratadas previamente com formulação pó-molhável ou calda contendo B. subtilis, respectivamente. Com base nesses resultados e sabendo-se que $\boldsymbol{H}$. glycines apresenta dependência de estímulo de exsudatos vegetais para eclosão e orientação das larvas, pode-se afirmar que $\boldsymbol{B}$. subtilis interfere nesse estímulo prejudicando o desenvolvimento do ciclo do nematóide.

Palavras-chave: Heterodera glycines, Bacillus subtilis, soja.

\section{SUMMARY}

The utilization of microorganisms for biological control of plant diseases has been studied in the world. In soybean cyst nematode (Heterodera glycines), an important diseases in soybeans, biological control strategies are important tools mostly because the lack of an efficient chemical control. The effect of Bacillus subtilis on $\boldsymbol{H}$. glycines was studied on greenhouse and laboratory experiments. The presence of $\boldsymbol{B}$. subtilis reduced the number of appeared $\boldsymbol{H}$. glycines eggs when under stimulus of soybean exudes. Also, treatment of soybean roots with $\boldsymbol{B}$. subtilis inhibited the juvenile larvae of $\boldsymbol{H}$. glycines migration towards the soybean roots. In greenhouse experiments using soil infested with eggs of $\boldsymbol{H}$. glycines, a reduction in the number of females was observed in the soybean root when both soil and seeds were previously treated with either wettable powder or solution containing $\boldsymbol{B}$. subtilis. Considering the results of this research, and that $\boldsymbol{H}$. glycines depends on plant exude for show up and orientation of larvae, it can be assumed that $\boldsymbol{B}$. subtilis might interfere in the nematode life cicle.

Key words: Heterodera glycines, Bacillus subtilis, soybean.

\section{INTRODUÇÃO}

Os nematóides fitoparasitas são responsáveis por grandes perdas na produção agrícola. Inúmeros microrganismos do solo são conhecidos como parasitas ou predadores de fitonematóides (SHARMA \& VIVALDI, 1999). A ação desses microrganismos pode ser resultante de efeito direto ou indireto através da interferência em etapas do ciclo vital do patógeno. Bactérias do

\footnotetext{
${ }^{1}$ Engenheiro Agrônomo, Doutorando em Proteção de Plantas, (UNESP/Botucatu), Professor do Curso de Agronomia, UNOESTE, Rodovia Raposo Tavares, km 572, 19067-175, Presidente Prudente, SP. E-mail: araujoff@terra.com.br. Autor para correspondência. ${ }^{2}$ Engenheiro Agrônomo, Doutor, EMBRAPA-CNPSo, CP 231, 86001-970, Londrina, PR.

${ }^{3}$ Engenheiro Agrônomo., Curso de Pós-Graduação em Microbiologia Agrícola, ESALQ/USP, CP 96, 13400-000, Piracicaba, SP.
} 
gênero Bacillus, principalmente $\boldsymbol{B}$. subtilis, além de componentes da população microbiana do solo, rizoplano e filoplano, apresentam características atrativas para os estudos de controle biológico de doenças de plantas (NORONHA et al., 1995). O potencial antagônico de bactérias foi estudado em vários trabalhos de controle biológico de doenças em plantas (BETTIOL \& KIMATI, 1990; KREBS $\boldsymbol{e t}$ al., 1993; SHARMA \& GOMES, 1999). Microrganismos rizosféricos, principalmente do gênero Bacillus, possuem um grande potencial de controle biológico de nematóides fitopatogênicos. NEIPP \& BECKER (1999), avaliando a atividade biocontroladora de isolados de rizobactérias sobre Heterodera schachtii, encontraram estirpes de bactérias, incluindo Bacillus megaterium, que reduziam a infecção de nematóides em beterraba. Anteriormente, KLOEPPER $\boldsymbol{e t}$ al. (1992) isolaram bactérias da rizosfera de plantas antagonistas à nematóides e encontraram espécies que exibiam um antagonismo a Heterodera glycines e Meloidogyne incognita em soja, com predominância de isolados do gênero Bacillus. Outros estudos evidenciaram o uso de bactérias como biocontroladoras de Heterodera glycines em soja, (TIAN et al., 2000 ; TIAN \& RIGGS, 2000). SIDDIQUI \& MAHMOOD (1995) concluíram que a aplicação de três microrganismos (Bacillus subtilis, Bradyrhizobium japonicum e Glomus fasciculatum) resultou em aumento da nodulação em feijão-guandu (Cajanus cajan) e redução da multiplicação de nematóide (Heterodera cajani).

O objetivo deste trabalho foi estudar a interferência de Bacillus subtilis em etapas do ciclo de vida de Heterodera glycines, observando o efeito da bactéria no desenvolvimento do nematóide para infecção de raízes de soja.

\section{MATERIAL E MÉTODOS}

Estirpe de $B$. subtilis - O isolado utilizado nesse trabalho foi a estirpe AP-3 de Bacillus subtilis. Essa estirpe foi isolada do filoplano de arroz, sendo caracterizada como de grande potencial inibitório ao desenvolvimento micelial de fungos fitopatogênicos (BETTIOL \& KIMATI, 1990). A bactéria foi multiplicada em meio de cultura Batata-dextrose (BD) durante sete dias a $25^{\circ} \mathrm{C}$, sob agitação constante de $130 \mathrm{rpm}$. Após esse período a calda, contendo a bactéria, foi utilizada diretamente nos experimentos em concentração final de $2,0.10^{8}$ células $/ \mathrm{m} \ell$ determinada pela técnica de número mais provável (NMP) em placas. Para formulação do Pó Molhável (PM) a calda foi centrifugada (5000rpm) e o precipitado misturado a caulinita e surfactantes com posterior secagem em equipamento "spray-drier" para concentração final de $2,0.10^{8}$ células/g do produto.

Teste de inibição de desenvolvimento de Heterodera glycines na rizosfera - Foram utilizados vasos plásticos contendo $1,0 \mathrm{~kg}$ de mistura areia:solo $(1: 1 \mathrm{v} / \mathrm{v})$. Os vasos foram acondicionados em casa de vegetação na qual foi conduzido o experimento. Sementes de soja (Glycine max) cv. BR-37 foram tratadas com a formulação PM contendo B. subtilis nas dosagens de $1000 \mathrm{~g}$ e $500 \mathrm{~g}$ para $50 \mathrm{~kg}$ de semente correspondendo, respectivamente, à concentração de $1,0.10^{6}$ e 5,0.10 células/semente, seguindo-se a semeadura nos vasos (uma semente/vaso). Outro tratamento foi conduzido com adição da calda bacteriana diretamente no solo 30 minutos antes da semeadura. Nesse caso, foi determinada uma concentração em torno de $1,0.10^{8}$ células/g de solo. Após onze dias da semeadura foram introduzidos ovos de nematóide (Heterodera glycines), na concentração de 4.000 ovos/vaso. Os ovos foram adicionados através de um orifício com $1 \mathrm{~cm}$ de diâmetro no solo distante $2 \mathrm{~cm}$ da haste da planta de soja.

Cada tratamento foi composto por seis repetições. Além dos vasos com os tratamentos, foram conduzidos outros vasos para monitoramento da infecção pelo nematóide, sendo considerados tratamentos controle. Após 62 dias, foi realizada a coleta do experimento sendo avaliado o desenvolvimento das plantas, presença de cistos de nematóide na rizosfera e população de Bacillus na rizosfera.

$\mathrm{O}$ solo aderido às raízes foi coletado e após secagem $\left(45^{\circ} \mathrm{C}\right)$, foram retiradas amostras de $10 \mathrm{~g}$ de solo seco para diluição em $100 \mathrm{~m} \ell$ de água esterilizada. Após diluições sucessivas $\left(10^{-3}\right.$ a $\left.10^{-5}\right)$, o material foi submetido a choque térmico $\left(70^{\circ} \mathrm{C} / 10\right.$ minutos) visando selecionar as bactérias formadoras de esporos. Das diluições $10^{-4}$ e $10^{-5}$, foi retirado $0,1 \mathrm{~m} \ell$ e foi espalhado em placa de Petri contendo meio de cultivo BDA. As colônias formadas foram contadas e caracterizadas como pertencentes ao gênero Bacillus, de acordo com a metodologia descrita por LI \& ALEXANDER (1988). A partir dessa avaliação, foi determinada a concentração de Bacillus spp. em cada tratamento.

Teste de eclosão - Exsudatos de sementes de soja foram obtidos conforme metodologia descrita por NISHI (1995): $10 \mathrm{~g}$ de sementes de soja cv. ( BR-37 ) foram desinfectados superficialmente com hipoclorito de sódio e adicionados em recipiente com $100 \mathrm{~m} \ell$ de água deionizada estéril. Em seguida o material foi incubado a $25^{\circ} \mathrm{C}$, sob 
agitação constante e ausência de luz. As sementes foram removidas após 24 horas, e a solução contendo os exsudatos foi esterilizada por filtração através de filtro Millipore $0,45 \mu \mathrm{m}$. A solução que continha os exsudatos foi diluída 100x em água estéril, sendo utilizada posteriormente para estimular a eclosão de larvas jovens de $\boldsymbol{H}$. glycines. Câmaras plásticas medindo $10 \times 10 \times 3 \mathrm{~cm}$ foram montadas para avaliar a eclosão de nematóides através da inserção de peneira (10 mesh), coberta com papel absorvente, dentro da câmara. No fundo da câmara foi adicionada a solução que continha os exsudatos de soja até cobrir totalmente o papel absorvente sobre a peneira. Sobre o papel foi adicionado uma suspensão com 8000 ovos de H. glycines. Após sete dias, o número de juvenis eclodidos na solução contendo os exsudatos foi avaliado, sendo os mesmos em seguida descartados. Os ovos restantes foram novamente incubados na câmara, sendo realizada a mesma avaliação após oito dias.

Influência de $\boldsymbol{B}$. subtilis sobre a eclosão H. glycines- Foram conduzidos três ensaios para avaliar o efeito de $\boldsymbol{B}$. subtilis sobre a eclosão de $\boldsymbol{H}$.

glycines. No primeiro ensaio adicionaram-se $10 \mathrm{~m} \ell$ de calda contendo $\boldsymbol{B}$. subtilis na solução final com exsudatos de soja (diluídos 100X conforme citado anteriormente) estabelecendo-se uma concentração de $1,0.10^{7}$ células $/ m \ell$. Em seguida, esta solução contendo a bactéria foi colocada na câmara de eclosão descrita acima; a metodologia também foi igual à do experimento anterior.

No segundo ensaio, a calda com $\boldsymbol{B}$. subtilis foi centrifugada (4500rpm/20min.), para separar as células do sobrenadante visando ao tratamento da solução contendo os exsudatos e estabelecendo-se o mesmo procedimento anterior.

No último ensaio, $90 \mathrm{~m} \ell \mathrm{da}$

solução de exsudatos foi misturada com $10 \mathrm{~m} \ell$ de calda contendo em torno de $10^{8}$ células de $\boldsymbol{B}$. subtilis $/ \mathrm{m} \ell$. Após 24 horas a bactéria foi removida por centrifugação (4500rpm/20min.) e o sobrenadante contendo os exsudatos foi utilizado na câmara de eclosão. Todos os ensaios foram conduzidos com quatro repetições.

Teste de atração- Sementes de soja foram desinfectadas e colocadas para germinar em câmara gerbox. Após $72 \mathrm{~h}$ as raízes das plântulas foram imersas em suspensão contendo 5,0. $10^{8}$ células de $\boldsymbol{B}$. subtilis/m $\ell$. Aproximadamente $0,1 \mathrm{~m} \ell$ da suspensão aderiu ao sistema radicular da plântula. As mesmas foram plantadas em caixa acrílica $(9,0 \times 2,0 \times 1,5 \mathrm{~cm})$ contendo areia fina. $\mathrm{O}$ nematóide foi adicionado na forma de juvenis ou ovos no lado oposto à planta, distante $6,0 \mathrm{~cm}$ através de orifício na areia. Os blocos de areia foram umedecidos com $4,0 \mathrm{~m} \ell$ de água destilada e deixados em laboratório, sob temperatura de $28^{\circ} \mathrm{C}$, durante dez dias. Os blocos de areia foram separados em seções de $1,0 \mathrm{~cm}$ com auxílio de um escalpelo. $O$ número de juvenis por seção foi determinado separando-se os nematóides da areia por flutuação e decantação. A avaliação do experimento, no qual se utilizaram juvenis de $\boldsymbol{H}$. glycines foi realizada com sete dias, enquanto no experimento em que se utilizaram ovos, a avaliação foi realizada com doze dias de incubação.

O delineamento experimental utilizado foi inteiramente casualizado com quatro repetições e utilizou-se o teste de Tukey para comparação de médias dos tratamentos.

\section{RESULTADOS E DISCUSSÃO}

A atração de Bacillus por exsudatos radiculares tem sido estudada na espermosfera (FUKUI $\boldsymbol{e t}$ al., 1994); na rizosfera esta atração pode estar relacionada com produção de hormônios por estirpes de Bacillus (ARAÚJO, 1995). Bacillus subtilis é um agente eficiente de controle biológico sendo utilizado freqüentemente no controle de fitopatógenos de solo, sendo esse efeito devido, principalmente, à produção de antibióticos (MATSUNO et al., 1992). Esse mecanismo desenvolvido na rizosfera influencia outros habitantes de solo de forma positiva ou negativa. ARAÚJO (1995) concluiu que o tratamento de semente de soja com Bacillus spp. junto ao Bradyrhizobium japonicum teve efeitos benéficos para a nodulação e desenvolvimento da planta; esse

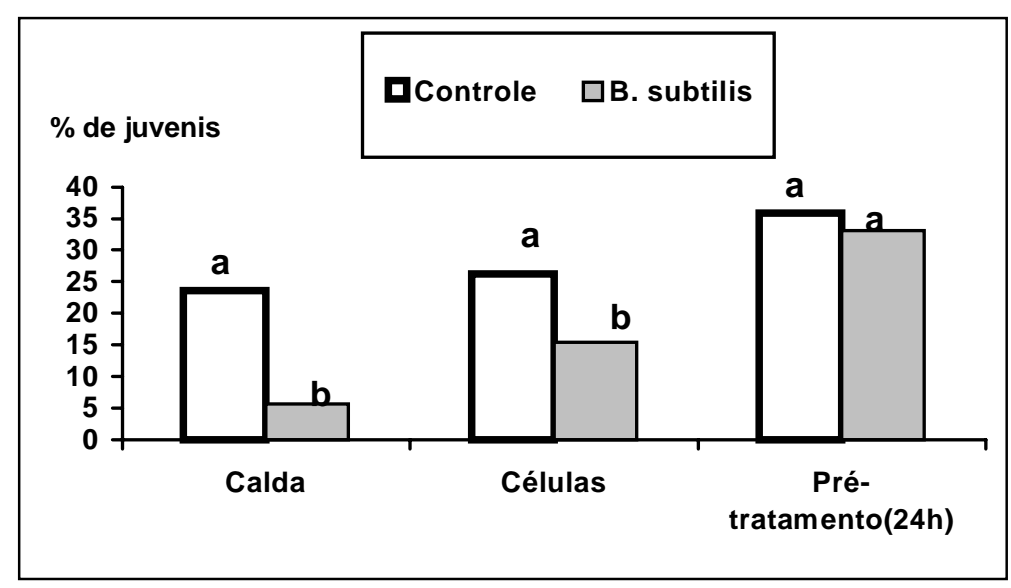

Figura 1 - Influência do tratamento de exsudatos de soja com Bacillus subtilis na eclosão de $H$. glycines após quinze dias. Colunas com letras diferentes são significativas pelo teste de Tukey .

Ciência Rural, v. 32, n. 2, 2002. 
mesmo tratamento reduziu a incidência de fungos nas sementes.

A calda contendo $\boldsymbol{B}$. subtilis reduziu significativamente a eclosão de juvenis de $\boldsymbol{H}$. glycines in vitro comparando-se com exsudatos não tratados com a bactéria (Figura 1). O tratamento em que se utilizou separadamente as células de $\boldsymbol{B}$. subtilis reduziu a eclosão de H. glycines, embora num patamar inferior à utilização da calda bruta. O prétratamento dos exsudatos por 24 horas com $\boldsymbol{B}$. subtilis não foi suficiente para reduzir, significativamente, a eclosão de juvenis em comparação ao controle.

A interferência no processo estimulatório para eclosão de juvenis de Heterodera glycines foi o efeito mais considerável encontrado com a bactéria testada nesse trabalho. Esse mesmo efeito associado à redução de penetracão de $\boldsymbol{H}$. schachtii foi encontrado tratando-se beterraba com rizobactérias (OOSTENDORP \& SIKORA, 1990). O mecanismo que interfere no estímulo à eclosão deve estar relacionado a metabólitos produzidos no desenvolvimento da bactéria, pois a utilização de células separadamente não proporcionou a mesma redução encontrada quando do uso da calda com a bactéria. Bergmann \& Van Duuren (1959) citados por OOSTENDORP \& SIKORA (1990) observaram uma completa inibição da eclosão de H. schachtii por filtrados de culturas bacterianas. Por outro lado, o contato direto da calda contendo B. subtilis com juvenis de $\boldsymbol{H}$. glycines recém-eclodidos, não ocasionou redução significativa da população de nematóide após sete dias de incubação.

A migração de $\boldsymbol{H}$. glycines para as raízes de soja foi influenciada pela presença de $\boldsymbol{B}$. subtilis. Os juvenis migraram até $4 \mathrm{~cm}$ de distância do ponto repeticões.

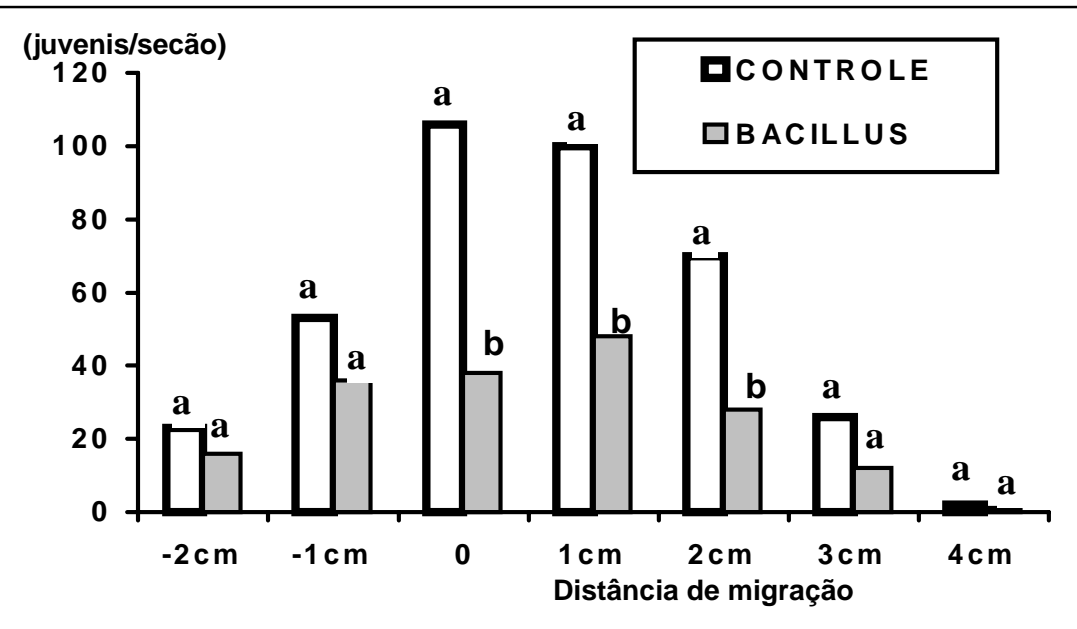

Figura 2 - Influência do tratamento de raiz de soja com Bacillus subtilis na orientação de juvenis de Heterodera glycines para as raízes. Avaliação realizada após sete dias. Diferenças significativas do controle de acordo com o teste de Tukey. Médias de quatro

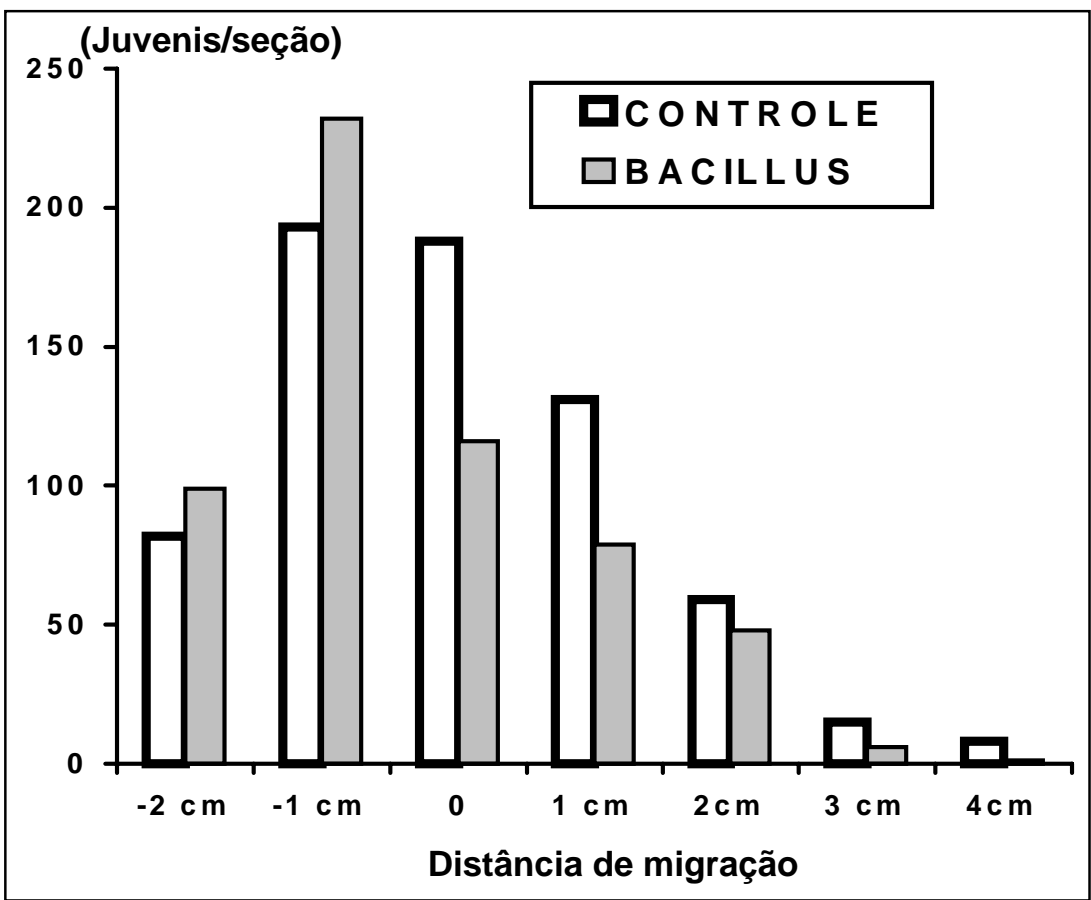

Figura 3 - Influência do tratamento de raiz de soja com Bacillus na orientação de juvenis de Heterodera glycines para as raízes. Avaliação realizada após 12 dias do plantio. Valores não diferiram significativamente através do teste de Tukey. Médias de quatro repeticões.

inicial até a planta. A maioria de juvenis migrou em média $2 \mathrm{~cm}$, sendo que parte desses juvenis também migraram no sentido oposto à planta. A presença de B. subtilis afetou a orientação do nematóide reduzindo a migração em direção a raiz de soja tanto no experimento que utilizou juvenis quanto no que utilizou ovos de H. glycines (Figuras 2 e 3 ). 
O efeito de $\boldsymbol{B}$. subtilis na migração de $\boldsymbol{H}$. glycines revelou que a interferência na orientação provocou dispersão dos juvenis mais desordenadamente do que nos tratamentos que não receberam a bactéria. Este resultado pode ser interpretado como uma degradação bacteriana dos componentes dos exsudatos que estimulam a migração dos juvenis recém eclodidos. A redução da presença de cistos na rizosfera de soja tratada com B. subtilis, em casa de vegetação, pode ter sido devido a interferências nos processos de eclosão e orientação de juvenis de $\boldsymbol{H}$. glycines. A hipótese de redução na penetração do nematóide nas raízes pode ser esclarecida como habilidade da bactéria envolver-se ou ligar-se às lectinas de superfície, que neste caso pode ser mínima devido à bactéria ser gram-positiva. Em solo pausterizado, rizobactérias reduziram a infecção por nematóide, variando de 45 a $68 \%$ em várias culturas (SIKORA, 1988). Esse mesmo autor cita que o efeito das rizobactérias está relacionado com a eclosão de juvenis ou eficácia de feromônios para atração dos machos.

Os resultados encontrados com o tratamento das sementes de soja com Bacillus subtilis demonstraram ter havido uma redução, significativa, em cerca de $70 \%$, da presença de cistos de nematóides viáveis nas raízes das plantas, quando se trataram as sementes com a formulação PM na dosagem $1000 \mathrm{~g} / 50 \mathrm{~kg}$ de semente. No caso da adição

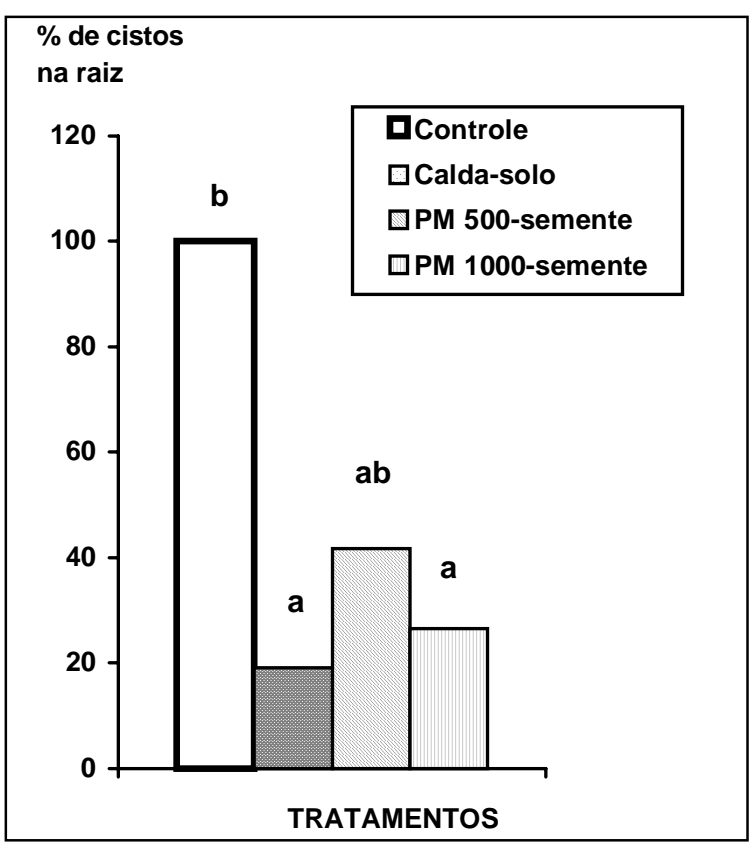

Figura 4 - Influência de B. subtilis aplicado em tratamento de solo ou de semente na incidência de cistos de $\boldsymbol{H}$. glycines na rizosfera de soja, em plantas com 62 dias de idade. Colunas com mesma letra não diferem estatisticamente pelo teste de Tukey. direta de $\boldsymbol{B}$. subtilis no solo (conc. inicial de $1,0.10^{7}$ cels./g de solo), a redução da presença de cistos foi maior em cerca de $80 \%$ de controle (Figura 4).

A colonização e distribuição uniforme das bactérias na rizosfera é importante para eficiência no controle das infecções por nematóides. A concentração inicial do biocontrolador a ser introduzido tem de garantir população suficiente para o nível de controle esperado durante o ciclo da cultura. O número de unidades formadoras de colônias no inóculo que atualmente é aplicado via semente tem sido demonstrado como de extrema importância para se determinar o nível de atividade antagônica (RACKE \& SIKORA, 1992).

$\mathrm{Na}$ análise da população de Bacillus spp. na rizosfera, após a coleta do experimento, foi encontrado colonização dessas bactérias na ordem de $7,0.10^{6}$ cels./g no tratamento que recebeu $\boldsymbol{B}$. subtilis no solo. Colonizações inferiores foram encontradas no tratamento que recebeu a dosagem $500 \mathrm{~g}$ da formulação/50kg de sementes e no tratamento controle, esses dois tratamentos expressando colonização da ordem de $10^{4}$ céls/g de solo (Figura 5). Como não foram utilizados marcadores genéticos para identificação da estirpe de $\boldsymbol{B}$. subtilis usada no solo, não se pode confirmar se as colônias detectadas na avaliação eram dessa estirpe, contudo a morfologia em ágar e visualização das células em microscópio permite identificar a estirpe de $\boldsymbol{B}$. subtilis utilizada. 
Neste trabalho, não foi determinada a população final da estirpe testada de $\boldsymbol{B}$. subtilis,

especificamente, devido ao não emprego de marcadores. Entretanto, pela semelhança das colônias detectadas na população com a da referida estirpe, além da população reduzida de Bacillus spp. no tratamento controle, pode-se afirmar que a maioria das colônias detectadas foi de $\boldsymbol{B}$. subtilis utilizada no inóculo inicial. Esta afirmação é reforçada pelo fato de que existiu redução significativa da infecção por $\boldsymbol{H}$. glycines nas plantas tratadas com B. subtilis.

Os resultados encontrados neste trabalho reforçam a tese de que o controle biológico de nematóides em plantas através de rizobactérias não seja devido a um efeito direto do biocontrolador sobre o nematóide. A interferência em algum estádio do ciclo de vida do nematóide pode ser a explicação mais coerente para o controle encontrado nos bioensaios com rizobactérias. Essa interferência pode estar relacionada com fatores químicos ou metabólicos envolvidos na interação de diversos microrganismos de solos.

\section{AGRADECIMENTOS}

Este trabalho foi financiado parcialmente pela Turfal Ind.e Com. Ltda (Curitiba, PR)

\section{REFERÊNCIAS BIBLIOGRÁFICAS}

ARAÚJO, F.F. Efeito de Bacillus spp e seus metabólitos na competitividade e na nodulação da soja (Glycine $\max [\mathrm{L}$. Merrill) por Bradyrhizobium spp. Londrina, 1995. 117p. Dissertação (Mestrado em Microbiologia) - Universidade Estadual de Londrina, 1995.

BETTIOL, W., KIMATI, H. Efeito de Bacillus subtilis sobre Pyricularia oryzae agente causal de bruzone do arroz. Pesquisa Agropecuária Brasileira, v.25, p.1165-1174, 1990.

FUKUI, R., POINAR, E.I., BAUER, P.H., et al. Spatial colonization patterns and interaction of bacteria on inoculated sugar beet seed. Phytopathology, v.84, p.1338-1345, 1994

KLOEPPER, J.W., RODRIGUEZKABANA, R., MCINROY, J.A. et al. Rhizosphere bacteria antagonist to soybean cyst (Heterodera glycines) and root-knot (Meloidogyne incognita) nematodes identification by fatty-acid analysis and frequency of biological control activity. Plant and Soil, v.139, n.1, p.75-84, 1992.

KREBS, B., JUNGE, H., OCKHARDT, A., et al. Bacillus subtilis: an effective biocontrol agent. Pesticides Sciences, v.37, p.427-429, 1993

LI, D.M., ALEXANDER, M. Co-inoculation with antibiotic-

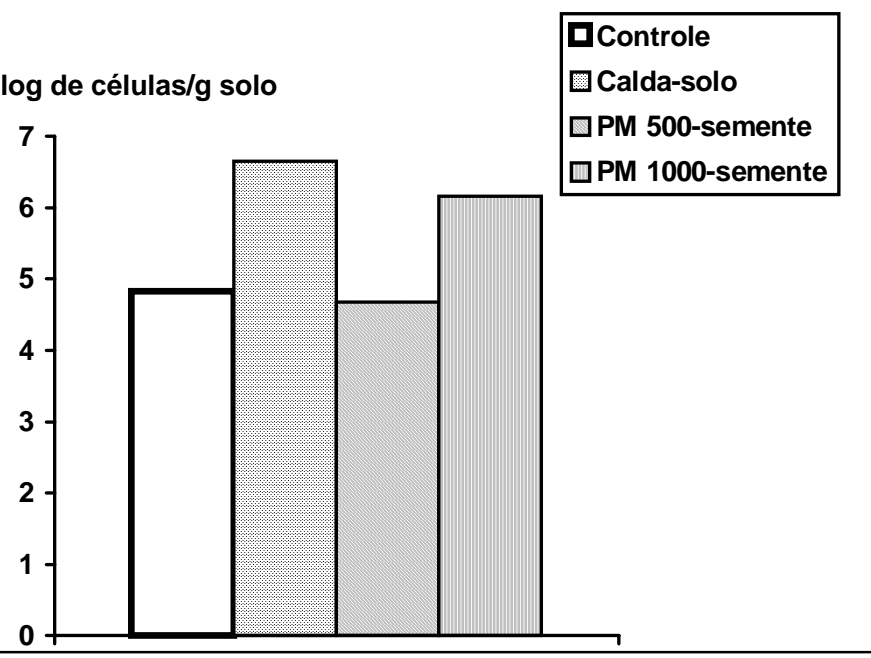

gura 5 - Colonização da rizosfera de soja por Bacillus spp., em plantas inoculadas com ovos de $\boldsymbol{H}$. glycines. Avaliação após 62 dias de plantio. Experimento conduzido em casa de vegetação.

producing bacteria to increase colonization and nodulation by rhizobia. Plant and Soil, v.108, p.211-219, 1988.

MATSUNO, Y., ANO, T., SHODA, M. Cloning of a gene responsible for the specific production of an antifungal antibiotic iturin with $n-\mathrm{C}_{16}-\beta$-amino acid residue. Journal of General and Applied Microbiology, v.38, p.505-509, 1992.

NEIPP, P.W., BECKER, J.O. Evaluation of biocontrol activity of rhizobacteria from Beta vulgaris against Heterodera schachtii. Journal of Nematology, v.31, n.1, p.54-61, 1999.

NISHI, C.Y.M. Infecção, competitividade e eficiência da fixação biológica do nitrogênio em soja (Glycine max [L.] Merrill) inoculada com as estirpes de Bradyrhizobium SEMIA 566, SEMIA 586, SEMIA 5079 e SEMIA 5080. Londrina, 1995. 110p. Dissertação (Mestrado em Microbiologia) - Universidade Estadual de Londrina, 1995.

NORONHA, M.A., MICHEREFF, S.J., MARIANO, R.L.R. Efeito do tratamento de sementes de caupi com Bacillus subtilis no controle de Rhizoctonia solani. Fitopatologia Brasileira, v.20, n.2, p.174-178, 1995.

OOSTENDORP, M., SIKORA, R.A. In vitro interrelationships between rhizosphere bacteria and Heterodera schachtii. Revue Nématol. v.13, p.269-274, 1990.

RACKE, J., SIKORA, R.A. Isolation, formulation and antagonistic activity of rhizobacteria toward the potato cyst nematode Globodera pallida. Soil Biol Biochem, v.24, p.521-526, 1992.

SIDDIQUI, Z.A., MAHMOOD, I. Biological control of Heterodera cajani and Fusarium udum by Bacillus subtilis, Bradyrhizobium japonicum and Glomus fasciculatum on "pigeonpea". Fundam. Appl. Nematol, v.18, p.559-566, 1995.

SHARMA, R. D., GOMES, A. C. Controle biológico de Meloidogyne arenaria com Pausteria penetrans. Nematologia Brasileira, v.23, n.1, p.47-52, 1999. 
SHARMA, R.D., VIVALDI, L.J. Controle de Meloidogyne javanica com Pausteria penetrans. Pesquisa Agropecuária Brasileira, v.34, n.11, p.2065-2069, 1999.

SIKORA, R.A. Interrelationship between plant health promoting rhizobacteria, plant parasitic nematodes and soil microorganisms. Med Fac Landbouww Rijksuniv Gent, v.53, n.2b, p.867-878, 1988 .

TIAN, H.L., RIGGS, R.D., CRIPPEN, D.L. Control of soybean cyst nematode by chitinolytic bacteria with chitin substrate. Journal of Nematology, v.32, n.4, p.370-376, 2000.

TIAN, H.L., RIGGS, R.D. Effects of rhizobacteria on soybean cyst nematode, Heterodera glycines. Journal of Nematology, v.32, n.4, p.377-388, 2000.

Ciência Rural, v. 32, n. 2, 2002. 